\title{
CANNULATION OF THE BOVINE DUCTUS DEFERENS FOR QUANTITATIVE RECOVERY OF EPIDIDYMAL SPERMATOZOA*
}

\author{
R. P. AMANN, J. F. HOKANSON AND J. O. ALMQUIST \\ Dairy Breeding Research Center, Department of Dairy Science \\ and Department of Veterinary Science, Pennsylvania State University, \\ University Park, Pennsylvania, U.S.A.
}

(Received 6th February 1963)

\begin{abstract}
Summary. A cannula and collection system are described which permit continuous quantitative recovery of the sperm effluent from the proximal ductus deferens without contamination by accessory gland fluids. In addition to concentric polyethylene cannulae, it features a $90^{\circ}$ copper elbow soldered at one end to a copper flange which is sutured to the posterior neck of the scrotum. The cannulae are directed through the elbow into an easily removable collection vial. In the first two bulls unilaterally cannulated, daily samples of about $2.8 \times 10^{9}$ spermatozoa were obtained via the cannula for more than 3 and 9 weeks.
\end{abstract}

\section{INTRODUCTION}

A method for obtaining successive samples of epididymal spermatozoa without contamination by accessory gland secretions is desirable for studying many aspects of spermatozoan and epididymal physiology. For some studies a ductus deferens fistula, as described by White, Larsen \& Wales (1959) for rams and more recently for bulls by Bennett \& Rowson (1963), would be satisfactory. However, for certain studies quantitative and continuous collection may be essential. Early attempts to cannulate the ductus deferens using silicone rubber tubing were discouraging (Walton, 1956), but it was felt that the use of tissuereaction-free polyethylene tubing might permit permanent cannulation and quantitative sperm recovery. This preliminary report concerns the successful development of such a cannula.

To avoid contamination and allow continuous sperm recovery, it was decided to collect the sperm effluent in a plastic vial attached to the bull or the cannula. Our initial attempt involved an anterior scrotal cannulation combined with a collection device sutured to the abdominal floor. This required a long, exteriorized cannula which was rather inflexible and as a result normal movements of the bull tore the cannula out in a few days. This method was abandoned in favour of one in which a collection device was sutured to the posterior surface of the scrotum.

* Authorized for publication on 28th January, 1963, as Paper No. 2741 in the journal series of The Pennsylvania Agricultural Experiment Station. 


\section{MATERIALS AND METHODS \\ GANNULA AND GOLLEGTING DEVIGE}

The cannula system was fabricated from polyethylene tubing (Clay Adams, Inc, Intramedic PE-50, PE-200, and PE-280), sterilized with Nolvasan, and rinsed with sterile physiological saline solution. Two concentric cannulae (Text-fig. 1) were used to reduce the danger of blockage through kinking of the

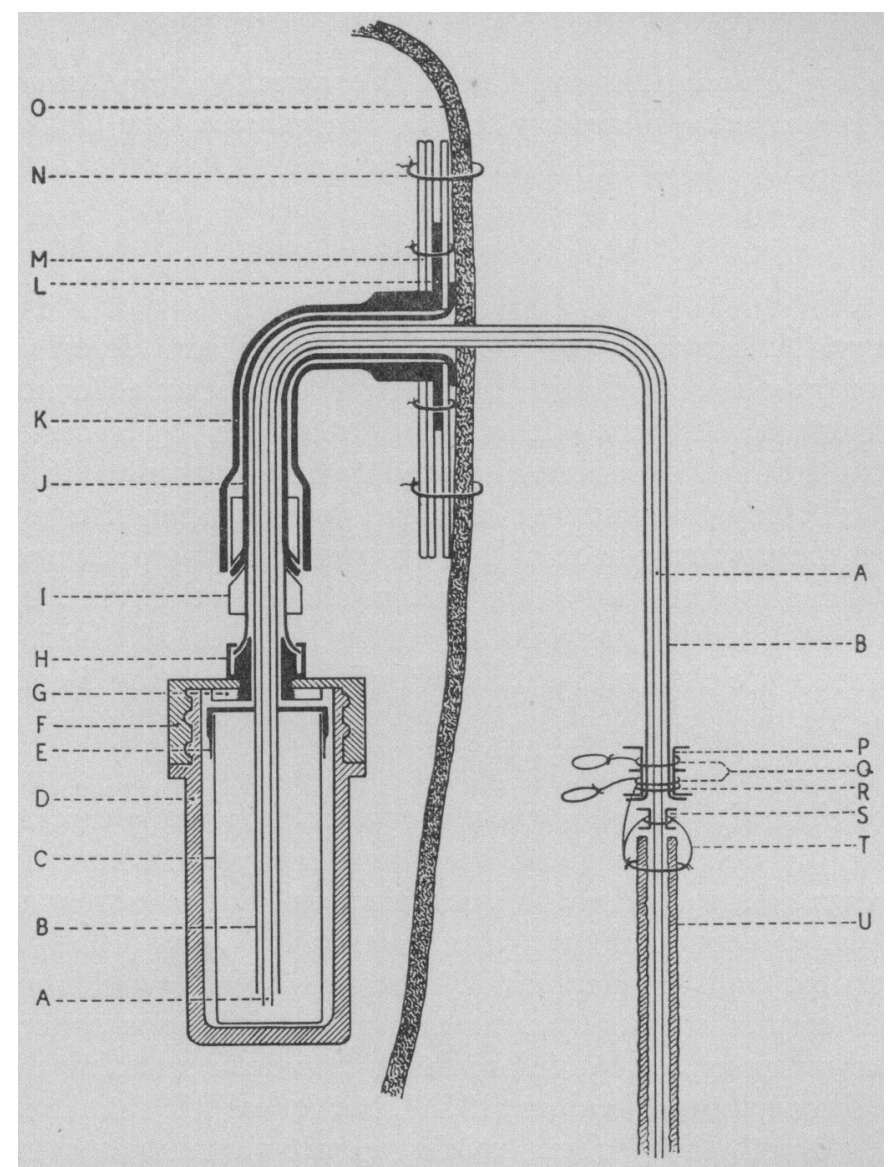

Text-Fig. 1. Cannulae and collecting device. Inner cannula, A; outer cannula, B; inner collection vial, $\mathrm{C}$; outer collection vial, $\mathrm{D}$; inner collection vial cap, $\mathrm{E}$; outer collection vial screw cap, F; nut for male Luer-lok fitting, $G$; male Luer-lok fitting, $H$; female Luer-lok fitting, I; PE-280 tubing, J; copper elbow ( $\frac{3}{8}$ in.), K; copper flange, L; plastic plates around copper flange, $M$; suture holding collection device to scrotum, $N$; scrotal wall, $\mathrm{O}$; outer cannula collar, $\mathbf{P}$; sutures holding outer collar to tunica vaginalis, $Q$; suture of outer collar to ductus deferens, $\mathrm{R}$; inner cannula collar, $\mathrm{S}$; sutures holding inner collar to ductus deferens, $T$; ductus deferens, $U$.

thin-walled tubing. The inner cannula (A) and outer cannula (B) were held in place at the point of insertion of the inner cannula into the ductus deferens (U) by suturing around snug-fitting collars ( $\mathrm{S}$ and $\mathrm{P}$, respectively) of slightly larger tubing.

The collecting device consisted of an inner polystyrene vial $(C)(19 \times 43 \mathrm{~mm})$ 
with a snug-fitting cap (E) contained in a heavy-walled polyethylene outer vial (D) $(22 \times 52 \mathrm{~mm})$ with a screw cap $(\mathrm{F})$. A male Luer-lok fitting $(\mathrm{H})$ was threaded through the outer vial cap (F) and held in place with a nut $(\mathrm{G})$. The two concentric cannulae passed through the Luer-lok fitting and entered the inner collection vial through a small hole in its cap. The use of Luer-lok fittings enabled rapid changing of the collection vials without sperm loss or annoyance to the bull. The device holding the collecting vials to the scrotum (Text-fig. 1) was a $\frac{3}{8}$-in. copper plumbing $90^{\circ}$ elbow $(\mathrm{K})$ soldered at one end to a $25 \times 30 \mathrm{~mm}$ copper flange (L) and soldered at the other end to a female Luer-lok fitting (I). The copper flange (L) was enclosed by three pieces $(42 \times 60 \times 1 \mathrm{~mm})$ of pliable polyethylene sheeting (M). To facilitate passage of the cannula through the copper elbow at the time of surgery, the elbow $(\mathrm{K})$ was lined with a piece of PE-280 polyethylene tubing ( $\mathrm{J}$ ) from the female Luer-lok fitting to the polyethylene plate adjacent to the scrotum. It was found advisable to tape the screw cap to the outer vial and to tighten the Luer-lok joint with pliers when changing vials. Before these precautions were adopted, the vial came off on several occasions.

\section{SURGERY}

The bull (about $1200 \mathrm{lb}$ ) was placed in lateral recumbency on a tilt table under general anaesthesia of intravenous Equithesin.* Using sterile techniques, a 6 to $8 \mathrm{~cm}$ incision was made in the right posterior neck of the scrotum immediately lateral to the septum. The spermatic cord was isolated by blunt dissection. Without displacement through the incision, the spermatic cord was rotated until the ductus deferens was located by palpation. A slightly smaller incision was made through the tunica vaginalis medial to the mesorchium to expose the ductus deferens. About $5 \mathrm{~cm}$ of the ductus deferens was isolated from adjacent blood vessels and nerves and freed from the reflection of the mesorchium. Caution was required to avoid vascular damage. The distal end of the isolated portion of the ductus deferens was ligated with synthetic suture material (Vetafil Bengen) and the duct was severed proximal to the ligation. Although not done in these experiments, it appears desirable to remove 2 to $3 \mathrm{~cm}$ of ductus deferens proximal to the ligation before inserting the cannula. This should simplify exteriorization of the cannula and reduce the possibility of kinking.

Several methods of cutting the ductus deferens for insertion of the inner cannula (PE-50, outer diameter $0.965 \mathrm{~mm}$ ) were tried. These included a longitudinal 1 to $2 \mathrm{~cm}$ slit in the wall of the ductus and a long oblique cut through the entire ductus deferens. Passage of the cannula was accomplished with least difficulty when the ductus deferens was cut in cross section to present a blunt end. Grasping the ductus deferens between thumb and fore-finger, the inner cannula was manipulated with the other hand as far as possible into the lumen of the ductus deferens; about 8 to $12 \mathrm{~cm}$ was inserted before marked resistance from the convoluted portion of the duct was encountered. The inner collar (S) was positioned against the severed end of the ductus deferens and

* Jensen-Salsbery Laboratories: $328 \mathrm{~g}$ chloral hydrate, $75 \mathrm{~g}$ pentobarbital, and $164 \mathrm{~g}$ magnesium sulphate per $500 \mathrm{ml}$; in aqueous solution of $35 \%$ propylene glycol and $9.5 \%$ alcohol. 
fixed to it by sutures (T) (Text-fig. 1). The outer cannula (B) was then positioned against the inner collar $(S)$ and fixed by suturing $(R$ and $Q$, respectively) the outer collar $(\mathrm{P})$ to both the ductus deferens and the tunica vaginalis. This latter step was considered important in preventing subsequent kinking of the cannula.

After the cannulae had been directed through the dorsal end of the incisions, the tunica vaginalis was sutured with 000 intestinal catgut. Penicillin and streptomycin were applied topically in the area. Finally, the scrotal skin was closed with interrupted mattress sutures of Vetafil Bengen and a purse string suture was placed around the cannulae. At this point, about $20 \mathrm{~cm}$ of the two cannulae were extended through the posterior scrotal neck. The cannulae were carefully inserted through the polyethylene tube $(J)$ lining the elbow $(K)$ of the collecting device which was then positioned on the scrotal neck. Eight double sutures of heavy Vetafil Bengen (N) were placed in the scrotal wall (O) with the exterior loops passing through plastic buttons (Plate 1). The use of plastic buttons was necessary to prevent the sutures from cutting through the skin. The free ends of the sutures were passed through holes in the plastic flange plates and tied. This held the collecting device snugly to the neck of the scrotum. The inner and outer cannulae were cut off with about $8 \mathrm{~cm}$ exposed and their ends sealed by heat and pressure. After $24 \mathrm{hr}$, the cannulae were trimmed to length and the collecting vials attached. Patency of the cannulation was then demonstrated by spermatozoa passing through the cannula when collection was made from the bull by artificial vagina; immediate patency was achieved.

\section{SUCGESS OF THE TECHNIQUE}

To date the technique has been used with two bulls. The first was slaughtered 50 days after surgery since virtual blockage of sperm passage had occurred on the 21 st day. Blockage probably resulted from infection due to opening of the cannulatory system; the collection vial fell off during the night on five occasions. It was subsequently taped on. After this time, daily samples contained only a few million spermatozoa each and epididymal inflammation became progressively more evident. The sutures holding the collection device to the scrotum had not been passed through buttons and had to be replaced on several occasions. With the second bull plastic buttons were used and the sutures did not pull out. The collection vial fell off once (Day 17) but infection did not result and the cannula was fully patent at slaughter on postoperative Day 69 .

Both bulls were sexually rested for the first 3 weeks after surgery. Nevertheless, means of 2.81 and $2.67 \times 10^{9}$ spermatozoa per day passed through the cannula. During the following 3 weeks, two successive ejaculates were collected each day by artificial vagina from both bulls. Daily outputs of spermatozoa for the non-cannulated sides averaged 2.92 and $3.37 \times 10^{9}$, respectively. For the second bull, spermatozoa per $24 \mathrm{hr}$ collected via the cannula averaged $2.86 \times 10^{9}$ during the period of ejaculation and $2 \cdot 82 \times 10^{9}$ during a subsequent 3 weeks of sexual rest. Thus, the number of spermatozoa passing through the cannula per $24 \mathrm{hr}$ was the same at sexual rest and during twice daily ejaculation, and similar to that obtained by ejaculation from the contralateral testis. 


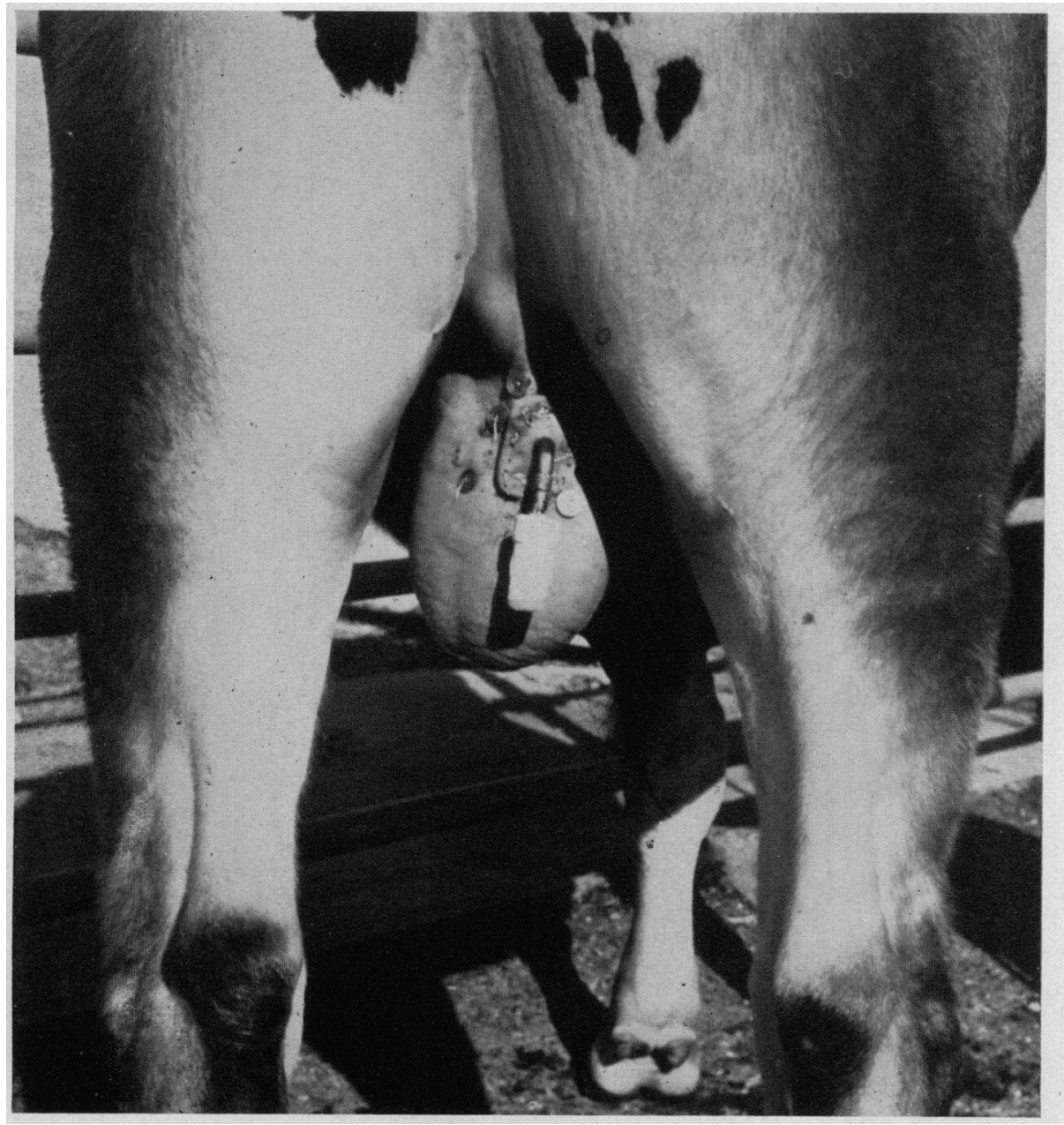

Collecting device in place 67 days after surgery. Two sutures had been replaced on Day 6.5 because the knots untied.

(Facing p. 68) 
REFERENCES

BennetT, J. P. \& Rowson, L. E. A. (1963) A fistula for the collection of epididymal semen from the bull. F. Reprod. Fertil. 6, 61 .

Walton, A. (1956) The initiation of motility in mammalian spermatozoa. Studies on Fertility, 8, 53.

WhITE, I. G., LARsen, L. H. \& WALEs, R. G. (1959) Method for the in vivo collection of epididymal spermatozoa and for their comparison with ejaculated cells. Fertil. Steril. 10, 571. 